\title{
A FORMAÇÃO DA PRIMEIRA REDE DE VILAS NO RIO GRANDE DE SÃO PEDRO*
}

Singular importância possuiu, no desenvolvimento do Brasil colonial, a criação de vilas, não só pelo fato de terem originado diversas das cidades e metrópoles atuais, mas por representarem o início da vida administrativa lo cal, constituindo-se numa das mais importantes contribuições portuguesas à cultura brasileira: o municipalismo.

A criação da vila, com a conseqüente organização da Câmara Municipal, fornece, por outro lado, uma visão das características sócio-econômicas do local, contribuindo não só para o conhecimento da História, como para a elucidação de aspectos correlacionados à Sociologia e à Economia, permitindo uma visão geral e mais aprofundada das caracteristicas locais e seu posionamento dentro da circunscrição geo-econômica ou administrativa em que se situa.

Mais especificamente, em se tratando da gênese das vilas e da sua evolução, há necessidade de situar, no tempo e no espaço, as condições dessa formação.

No caso rio-grandense em foco, há que se considerar, inicialmente, sua especificidade povoadora pelo fato de, somente no século XVIII, incorporar-se ao território brasileiro. Sua efetivação, originada na economia pecuária com base topográfica favorável e mantida na força das armas, dado o confronto com os insistentes avanços da dominação espanhola, tornou o Rio Grande de São Pedro palco de lutas, entremeadas de constante alerta militar.

Dai que esse binômio de dominação ecônomo-política moldou a gênese dos núcleos populacionais sulinos.

Assim, um primitivo pouso de tropeiros, um curral, um passo de um rio, ganhava importância na fixação do povoamento. Igualmente, a instalação de presidios, fortes, guardas e acampamentos militares paulatinamente transformavam-se em concentrações populacionais (1) que raramente conservavam sua feição inicial, pois fatores diversos de sua evolução davam outro caráter à região.

Da mesma forma, atendendo a objetivos geo-econômicos e estratégico-militares (2), a circunstancial doação de uma sesmaria ou data de terra (3), aqui ou acolá, ou a edificação de uma capelinha por um estancieiro mais fervoroso, atraindo vizinhos geralmente longinquos, transformava o espaço numa verdadeira rede de pontos esparsos, onde uns se interligavam e outros se isolavam, à margem de um processo unificador que atava o sul ao norte do território. 
A exemplo do povoamento brasileiro, foi o litoral rio-grandense palco inicial desta rede, pela proximidade da costa, e a área explorada facilitou o escoamento do gado em pé e as trocas comerciais. Aos poucos, transpostas as barreiras geográficas do planalto, o centro, agora zona nova, passou a ser atração dominante, ocorrendo as migrações com esperança de perspectivas mais promissoras.

O século XVIII e, principalmente, o século XIX, ainda sob o signo colonial, com base no sistema imposto e desvirtuado de racionalidade e coerência na exploração dos recursos do território, a fim de satisfazer as necessidades materiais da população, assistiram a instabilidade do povoamento do Rio Grande. Dai algumas aglomerações urbanas isoladas, de baixa densidade demográfica, sobretudo marginalizadas do processo de produção e consumo, que anima e transforma as povoações.

Conclui-se logo que a atividade econômica, em regra, é que caracterizou a linha e os rumos do povoamento, que, a exemplo da pecuária, se alastrou por contigüidade. Era uma herança do Brasil colonial, pois:

Sistema de fôrças geradoras de condiçōes, instituiçoes, códigos, oficios, riquezas, comunicaçoes, transporte, migraçōes, a estrutura econômica ofereceu sempre os meios para que funcionasse o processo urbanizador.

O programa da metrópole com relação às capitanias brasileiras era a extração das riquezas naturais e a criaça de fontes agricolas de produtos de forte consumo europeu, bem como incremento de massas consumidoras de mercadorias portuguêsas. Portanto, puras cogitaçoes de ordem econômica inspiram a emprêsa colonizadora.

Assim, a construçăo das cidades brasileiras nunca perdeu de vista o interêsse geral da economia (...). Por isso mesmo, a cidade que surge já está incutida dentro de um esquema econômico, seja do ciclo da cana, seja da produçáo de abastecimento, seja do couro ou da mineraçăo ou do comércio. (4)

Outrossim, a proximidade da rede de caminhos, picadas e estradas, rasgando terras desconhecidas ou referidas, permitindo o aparecimento de novas frentes de produção, atraiu o estabelecimento humano favorecido pelo comércio ali estabelecido.

Afirma Fernando de Azevedo que é

(...) em funçáo dos caminhos que as cidades crescem ou decrescem e se tornam núcleos de concentraçåo ou de distribuição de produtos agricolas ou industriais, (...). (5)

Nascidas nestas circunstâncias e seladas pela armadura militar, formaram-se as primitivas vilas ou cidades (6) do Rio Grande. Algumas destas, articuladas a partir de relações sócio-econômicas e pela concentração de atividades e serviços, polarizaram as demais, formando constelações urbanas, aglutinadoras de interesses regionais (7).

A evolução destes núcleos, futuras cidades, e a formação de redes sucessivas implicavam na caracterização da primitiva capela curada, que, após ter delimitado seu espaço físico pelas autoridades eclesiásticas, consituía uma freguesia. Posteriormente, dadas as circunstâncias ecônomo-politicas e administrativas, a mesma ganhava foros de vila. Chegava então o povoado à fase de sua maioridade ao adquirir o direito de eleger seus representantes. 
Enfim, a instalação da Câmara representava o coroamento desse processo de formação.

\subsection{A INSTALACCAO E O FUNCIONAMENTO DE UMA VILA}

Por um ato de decisão governamental (8), a pedido dos moradores que viam, nesse ato, a resposta aos seus anseios particulares e/ou comunitários, cujas circunstâncias muitas vezes favoreciam a petição, ou mesmo fruto de propostas políticas (9), transformava-se a então freguesia em vila, ganhando, além da característica eclesiástica que já detinha, cunho administrativo, e condicionada a exercer, através das Câmaras de vereadores, o papel de controle e desenvolvimento econômico, politico, social e cultural da sede e sua área municipal.

Convém salientar que, já como freguesia, além dos serviços de registros, seja de nascimento ou de casamentos e óbitos, cuidava também da comunicação de editais e avisos do governo e da recreação, promovendo festas religiosas e outras, além de colaborar na manutenção da segurança.

Sem dúvida, estes encargos, após a elevaçẫo de uma vila, continuavam a ser feitos nas freguesias do município, porém agora sob a jurisdição de sua sede.

Apesar das vantagens atribuídas à existência de povoados organizados administrativamente, os trâmites de sua efetivação arrastavam-se muitas vezes por vários anos $(10)$.

A evolução do municipio no Brasil, corporificada inicialmente ao arrepio das Ordenações e das Leis Extravagantes (11), é, após a Independência, que receberia tratamento mais definido e adequado à situação peculiar brasileira.

Nesse sentido, a Constituição Imperial, no seu Título VII, Capítulo II, artigos 167, 168 e 169, estatui, respectivamente:

Em tôdas as Cidades e Vilas ora existentes e nas mais que para o futuro se criarem haverá Câmaras, às quais compete o governo econômico e municipal das mesmas Cidades e Vilas.

As Câmaras serão eletivas e compostas de número de vereadores que a lei designar, e o que obtiver maior número de votos será Presidente.

O exercicio de suas funçōes municipais, formação das posturas policiais, aplicação das suas rendas, e todas as suas particulares e úteis atribuiçōes serão decretadas por uma lei regulamentar.

A lei referida surgiu a $1^{\circ}$ de outubro de $1828(12)$, revogando todos os direitos, leis e alvarás e mais resoluções que davam às Câmaras outras atribuições, e norteou, durante o Império, as finalidades e atribuições dos regentes das municipalidades, que visavam ser intérpretes da vontade do povo.

As posturas, através do seu Código, na maioria dos casos traduzia o alcance e o atendimento às necessidades da vila, estimulando, permitindo, delimitando, coibindo, cerceando, isto é, demonstrando nas suas entrelinhas, implícita ou explicitamente, sua rotina estagnadora ou seus impulsos de mudança.

Tal objetivo, o de estimulo, nem sempre presente pelos homens bons quando se reuniam em sessões ordinárias ou, às vezes, extraordinárias, pesava nos destinos da vila, aliada às dificuldades financeiras sempre presentes no contexto da Capitania e, depois, Província.

Os vereadores, em número de nove para as cidades e de sete para as vilas, 
conduziam a administração com o auxilio dos serviços do almotacé, procurador, juizes de paz, aferidor, arrematantes, arruadores, secretário, carcereiro e outros. Estes cargos não eram eletivos, com exceção dos vereadores e juizes de paz, estes proporcionais ao número de distritos. Mas, observa-se que, nem sempre, todas estas funções especializadas existiam em todas as vilas instaladas. No mais das vezes, aglutinavam-se os encargos nas mãos de poucos, de acordo com a condição política e sócio-econômica municipal (13).

No caso rio-grandense, transcorrido praticamente o periodo imperial, a inação das municipalidades é sentida e reclamada em 1872 pelo próprio Presidente da Provinvia Conselheiro Jerônimo Figueira de Mello, ao referir que:

Estas corporaø̧es, ás quaes pela Constituiçăo do Império está confiado o governo economico e municiapal das Cidadese Villas, continuâo a se dirigir no exercicio de suas attribuiçóes pela Lei Regulamentar do $1^{\circ}$ de Outubro de 1828.

Como sabeis, essa lei nåo preenche os fins que uma boa administração deve procurar attingir, já porque nella está confundida a execução com a discussão e resolução dos differentes assumptos, que cumpre serem providenciados, já porque lutão com deficiencia de rendas para poderem occorrer a muitas despezas urgentes, e já por que carecem.quasi sempre de pessoal que tenha habilitaçōes para o governo local, e quando o encontrâo, desanimåo em frente de obstaculos, que entorpecem sua boa vontade e seu zelo.

Para remediar estado tão pouco satisfactorio, posso dizervos que o Governo Imperial trata de examinar qual seja a mais proficiente reforma, que se póde adoptar para tirar as nossas Municipalidades da inacção em que vegetăo, e dar-lhes o mais conveniente impulso e animaçăo. (14)

A descentralização e autonomia municipais foram as diretrizes traçadas em 1888 pelo deputado Tavares (15) para remediar o mal de algumas vilas. Acontece que, até então, os municipios estavam excessivamente dependentes das Assembléias Provinciais, as quais legislavam sobre a economia municipal isto é, sobre a receita, a fiscalização das despesas, bem como da criação de impostos municipais, supressão ou criação de funções remuneradas, além da aprovação das posturas municipais.

Entretanto, os documentos, imagem viva dos fatos, revelam que, além destes condicionamentos de ordem administrativa, outros, sobretudo o de ordem geográfica, constituíram-se em barrreiras não só da expansão e formação de vilas como do seu desenvolvimento. De um lado, o relevo escarpado do planalto, estancando as comunicações, e, de outro, a existência de rios e lagoas de reduzida ou nula navegabilidade, desanimavam os habitantes a produzirem a nível de exportação, pois, com caminhos de difícil trânsito e escoamento, restava entregar-se praticamente à rotina das relações de produção a nível de subsistência, vez por outra estimulados por promessas ou tentativas frustradas de expansão e comunicação com outros centros consumidores.

Retrata essa realidade o nordeste rio-grandense durante o século XIX, então municipio de Santo Antonio da Patrulha, com base no processo evolutivo do seu vilamento e desmembramentos até o final do Império e na conjuntura provincial (16).

A IMPOSIÇAO DE UMA DIVISATO ADMINISTRATIVA-FASE DECISIVA

(1803-1809)

O século XIX nasceu para o Continente de São Pedro, já no seu primeiro ano, delineando paz e integração, através da incorporação definitiva das Mis- 
sões (1801), seguidas de uma série de medidas, que, tomadas ainda na primeira década, vieram moldar definitivamente as feições da estrutura ecônomo-política do território riograndense.

Sobretudo, foi o periodo de 1803-1809 significativo sob dois aspectos: de um lado, como freio das irregularidades e da grande crise que avassalava o Continente, seja na justiça, no comércio, na instrução, nus finanças; e, de outro, como modelador da sua divisão administrativa, ponto fundamental da estruturação da História Rio-grandense.

Ao assumir a administração do Rio Grande, Paulo José da Silva Gama (17) encontrou uma série de dificuldades, que procurou contornar nos seus quase sete anos de governo, através de uma política que objetivava, acima de tudo, atender aos interesses econômicos da Coroa.

Em meio à riqueza econômica traduzida no gado em pé, o gado vacum nos seus diferentes efeitos, como: carne, charque, cabelo, graxa e ossos, mais a uva, a farinha de mandioca, o trigo e outros cereais (18) aqui cultivados,era notória a decadência, a desordem e o abatimento financeiro da Capitania, conseqüente, de um lado, dos constantes atritos do Prata, onde adesgastante prontidão militar imperava como norma política do governo, e, de outro, da dependência rigorosa do governo rio-grandense ao do Rio de Janeiro, com as comunicações dificultadas pelas distâncias, fazia jazer o então Continente de São Pedro.

O contrabando desenfreado, as tropas desorganizadas e abandonadas, a justiça inexistente, a instrução nula, a indústria do charque abafada pela competidora platina, a agricultura sem agricultores, esta situação de verdadeiro marasmo pode ser aquilatada pelo amplo relato que o então governador fez do Continente e dirigiu ao Vice-Rei no Rio de Janeiro. Diz ele:

(...) O Contrabando que actualmente se estava fazendo portoda a Fronteira com os Espanhoes, introduzindo nos Gados Vacum e Cavallar, e Muar, e tambem effeitos manufacturados naquelle Paiz, que todo nos he ruinozo, porqe nós grande abundancia de toda esta qualidade de Gado, e lấa para semanefacturarem, os Cuxinilhos, e Ponxes como com effeito se manefacturåo, nesta Capitania toda aquella introdução nos hé prejudicial; estes contrabandistas Espanhoes, e Portuguezes os vendem aqui por deminuto preço aos charquiadores, de que se segue que os nossos Criadores tenhâo pouca extraçăo no seu Gado, e que todas estas imenças Campinas estejăo inundadas de Gado bravio pela dobrada multiplicação a respeito da extraçăo; este perniciozo abuzo tenho procurado evitar nomeando Offeciaes que pelas informaçoens, os julguei Capazes de Vigiar, e Confiscar para a Real Fazenda todo o Gado e Generos introduzidos pelos contrabandistas, o que já tem produzido mto bom effeito, em utilidade da Faz.da Real pelas tomadias que se tem feito esperançandome qe estas minhas deligencias Servirào de hum grande aumento e socego a Capitania, augmento porque os Criadores, e Commerciantes terâo maior extraçăo. Huns nos seos Gados, e outros nas suas fazendas; (...). (19)

\section{Em outro oficio da mesma data, complementa:}

(...) Os possuidores chamados Estanceiros, dezenfreando a sua insaciável cobiça: huns pertendem violentamente unir ás suas grandes pocessoens as pequenas datas dos Pobres seus Vezinhos: Outros nâo podendo Conter dentro dos lemites das suas terras os Gados por se multiplicarem em numaro exorbitante, innundåo com elles os Campos confinantes, destruindo as suas lavouras, e inposibilitando os seus cultivadores para nellas continuarem. Săo portanto os generos mais importantes do Paiz as Carnes, e a Coirama, e que em maior abundancia se exportåo. O resto hé insigneficante, (...). Desta forma dezamparada a Agricultura ja mais pode o paiz enriquecer-se, conhecese sencivelmente a grande falta de Dinheiro, porque os generos que se exportão apenas chegåo para compençar os que seimportão Com esta grande 
abundância de Carnes, e com a ociozidade dos abitantes Se dá ocazião a averem homens Vadios Vagamundos, como Sáo dezertores, e facionorozos que para aqui seacolhem onde achão hum azilo bem proporcionado. Os unicos Lavradores que há såo esses restos de Cazaes, que ainda seconservăo da forma que ja dice, de resto ninguem cultiva

A todas estas razoens, que são e tem sido a cauza dadecadencia desta Capitania, acrescido ainda o principio da ruina total, senão se atalhar. De todos os diferentes portos das Capitanias d'America estão sahindo commumente Embarcaçoens Portuguezas, que carregăo Copia imença de Escravactura, e a văo exportar direitamente a Monte Vedio, e Buenos Ayres, edela atroco desta mesma escravactura setornão novamente a Carregar de generos daquele paiz, como săo Trigos, Carnes, Cebos, Coiros... e os conduzem para os Portos donde sahirăo, ou selhe dá entrada francamente. (20)

Urgia, diante de tantas deficiências e problemas, num território tão rico em potencial, uma tomada de posição para assegurar o controle e minimizar esas irregularidades e, conseqüentemente, centralizar os devidos direitos da Coroa. Paulo da Gama providenciou na execução de medidas que propusera, através do estabelecimento de órgãos como: as Alfândegas de Porto Alegre (1803), e do Rio Grande de (1804), além da Junta da Real Fazenda Leopoldo, em substituição à antiga Provedoria, fundada em 1753.

Apesar destas medidas tomadas, o governador, já em 1803, previu que sua ação seria ineficaz administrando apenas com a Câmara de Vereadores de Porto Alegre, única em todo o território, dotado de vasta área e com a população aumentada (21), onde as dificuldades cresciam e as reclamações se sucediam, principalmente em relação à administração. Tornava-se urgente a subdivisão do Continente de São Pedro para uma ação mais rápida dos poderes que, complementado assim sua política administrativa, possibilitasse o melhor atendimento das populações locais.

Com esse intuito, dirigiu-se ao Principe Regente, representando as vantagens da criação de vilas e sugeriu, para maior comodidade, que se dividisse o Continente em quatro distritos, devendo ser Porto Alegre.

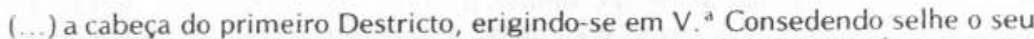
foral; qe ainda o năo tem proprio, porque apezar de que a Camara rezida prezentemente aqui, contudo o Foral pertence a Villa do Rio Grande de S. Pedro, onde nada há de Justiça, Incluindo-se neste primeiro Destricto as Freguezias de N. Sra . Madre de D.s de Porto Alegre, N. $\mathrm{Sr}^{2}$. da Conceição de Viamão, a do $\mathrm{Sr}$. Jezus do Triunfo, e de N. Sr ${ }^{\text {a }}$. dos Anjos d'Aldeia: vindo a Comporce todo este Destricto de 11227, almas exceto a Tropa de Linha, e recem-nascidos no prezente ANNO: No qual se Deve comservar toda a Justiça da mesma forma que existe

A Villa do Rio Grande de S. Pedro deve ser a Cabeça do Destricto daquella Fronteira do Sul, que já tem o seu Foral, eonde precize crear se huma nova Camara e toda a J ustiça Com respondente como a do Porto Alegre: devendo-selhe incluir tres Freguezias a Saber a primeira chamada do mesmo nome S. Pedro do Rio Grande com todas as suas Capellas filliaes, a de N. Sr ${ }^{a}$. da Conceição do Estreito, e a de S. Luis de Mostardas: e vem amontar a sua população em 11290 almas contadas como assima. A Freguezia de $\mathrm{N} . \mathrm{Sr}^{2}$. do Rozario do Rio Pardo deve da mesma forma ser erigida em Villa como Cabeça de todo aquelle destricto da Fronteira do Norte anexandoselhe todas as suas Capellas filliáes, ealem disso a Freguezla de N.Sra ${ }^{a}$. da Conceiçáo da Caxoeira, e de Sto. Amaro, e a de S. Jozé de Taquari: parecendome muito a propozito que aquella Povoação que tem o nome de Rio Pardo, se mude no de Villa do principe, criandolhe igualmente Justiça, eOfficiaes Competentes como as outras. Emonta a sua população em 9599 almas.

Finalmente a Freguezia de S.to Antonio da Patrulha Situada nas Cabeceiras do Rio Tramandi não deixa desefazer attendivel para ser criada em Villa, com o seu respectivo Foral, constituido-selhe huma Camara. Parecendo-me damesmaforma que 
esta seja novamente denominada com o titulo de Villa de Anadia, ficando como Cabeça de todo aquelle Destricto que comprehende para Sima daSerra, obstando-se aque os povos tenhão o grande incomodo da passagem dos Rios que quazi o cercão.

Em cuja devizão mais deve attender-se a commodidade dos Povos do que a sua população Anexandose-lhe as Freguezias de N.Snr ${ }^{2}$. da Olivr ${ }^{\text {a }}$. de Sima da Serra; ea de N.Snr ${ }^{2}$. da Conceição do Arroio, Compodo-se de $\mathbf{4 0 8 5}$ almas a sua população.

Ds G. de a V ${ }^{a}$ Ex ${ }^{\star}$. Porto Alegre 4 de Dezembro de 1803

Illmo. e Exmo. Snre. Visconde de Anadia.

Paulo Joze da Sa. Gama (22)

Tem-se presente representação como o primeiro ato em que se pensou dividir administrativamente o Continente Rio-grandense. Mas, quase simultaneamente ao pedido do governador, o sargento-mor Domingos José Marques Fernandes (23) foi a Portugal por sua conta sugerir ao rei a criação de vilas, para o que escreveu e dedicou ao Serenissimo Senhor uma Descrição Corográfica, Politica, Civil e Militar da Capitania do Rio Grande de S. Pedro do Sul, datada de 10 de setembro de 1804 .

Pela sua ordenação e lógica, é considerada por muitos como a Primeira História Gaúcha.

Ao presente estudo interessa desta descrição, sobretudo, o seu último capítulo, o quarto. Nele, além de instar a criação de vilas e competentes ministros de justiça para coibir as desordens e inclemências, depositou o proponente no nordeste rio-grandense ainda inculto e desprezado, o estimulo da prosperidade agrícola da Capitania, preterida em favor da pecuária rendosa aos cofres reais, como refere:

As melhores terras da Capitania do Rio Grande de S. Pedro do Sul para a agricultura infeliz e lastimosamente se acham incultas e perdidas; (..) as terras da Serra Geral sảo as mais excelentes que há: começa esta no Rio das Tôrres, que, como também se disse divide esta Capitania da de Santa Catarina e corre por espaço de ortenta léguas, até a guarda dos Ferreiros, ou bôca do Monte, com largura de oito léguas e mais

Podemos dizer que elas são as melhores terras, não só da Capitania do Rio Grande, mas de tồda a América; porque segundo a experiência, que há de algumas, que se têm provado, não só produzem tôda a espécie de legumes, mas também cana de açucar, com vantagem a tôdas as outras terras do Brasil na produção dêste gênero, e com excesso de trinta a quarenta por cento; o que se vê em alguns engenhos, que ali se acham já estabelecidos; para isto concorrem duas grandes adiçoes; muita madeira e boa; e rios navegáveis para o transporte: de maneira que não haverá lavrador distante da navegação, pela qual possa exportar os efeitos da sua fazenda mais de seis léguas, fáceis a carros. E é tal a fertilidade das mesmas terras, que um quarto de légua em quadro é bastante para o estabelecimento de um engenho de açucar do lote de cem escravos: quando nas outras Capitanias um engenho de açucar dêste mesmo lote pede meia légua quadrada. (24)

As então freguesias de Santo Antonio da Patrulha e Conceição do Arroio eram estimuladas a subtrair-se do processo marginalizante que então vinham sofrendo pela deslocação do eixo econômico para o centro, movido pela pecuá
ria.

Por outro lado, endossa a argumentação dos dois propositores as reflexões de Manoel Antônio de Magalhães em seu "Almanaque da Vila de Porto Alegre", escrito em 1808, sobre o estado atual da Capitania do Rio Grande de São Pedro, seu clima, comércio, agricultura, navegação, povos, magistratura, etc., que, no seu decorrer, afirma e recomenda: 
(...) Esta capitania, Exm. Sr., é uma cousa muito grande como ao longe se não póde pensar; a factura das vilas é da maior necessidade; (...) (25)

Assim é que d. João não ficou inerte e indiferente aos reclamos da extremidade meridional da Colônia.

Justifica-se, no contexto politico-administrativo do Rio Grande, a Carta de Lei de 19 de setembro de 1807, a qual desanexa do Rio de Janeiro a Capitania de São Pedro, ficando-lhe subordinada Santa Catarina, passo este que, facilitando a administração rio-grandense, acelerou sua subdivisão territorial.

Era o início mais agudo de um processo integrador. Correspondia à extensão ao Brasil do liberalismo econômico inaugurado em 1808, com a vinda da família real, através de atos régios, sobretudo o alvará de $1^{\circ}$ de abril de 1808 , permitindo o estabelecimento de fábricas de toda a qualidade e manufaturas, e ainda a Carta Régia de 28 de janeiro de 1808, que concedeu livre entrada no Brasil de todos os gêneros e efeitos, provenientes das nações amigas. Estes atos iniciaram o guadro de um processo ainda embrionário que delineou os rumos da evolução histórica brasileira, porém lembrando que, em regra geral, a politica econômica ainda era nitidamente a da fase colonial, como confirmą um estudioso da cultura brasileira:

O que caracteriza, fundamentalmente, a economia do séc. XIX é a persistência das formas coloniais, embora tocadas pelas modificaçoes inevitáveis impostas pelas circunstâncias históricas; a continuidade da produção de produtos primários destinados à exportação; a necessidade de importação de artigos manufaturados para consumo interno por parte da pequena população (...) (26).

Naturalmente, a Capitania do Rio Grande inserida neste contexto, atada ao centro do Brasil pelos caminhos das tropas, veia que regava e arregimentava a política econômica da Coroa, teria, na Provisão de 7 de outubro de 1809 , a resposta aos apelos para a sua organização administrativa, seladora da incorporação política e econômica de 1801 .

\section{A PRIMEIRA REDE DE VILAS: RIO GRANDE, PORTO ALEGRE, RIO PARDO E SANTO ANTONIO DA PATRULHA (1809)}

A formação dos primeiros núcleos populacionais no Rio Grande de São Pedro, nascidos sob diversas feições, foram, direta ou indiretamente, estimulados por impulsos econômicos (27), os quais, preservados politica e militarmente, desencadearam, durante o século XVIII, a aceleração do seu povoamento, com o reforço não só de elementos de outras Capitanias como através da vinda de casais açorianos.

Não fugindo à regra do caso brasileiro, inicialmente foi ocupado o litoral, tendo como fulcro Rio Grande. Mas, foi o Jacuí, com seus afluentes, o grande responsável pela radicação e irradiação populacional do centro do Continente cujas águas foram palco de sua paulatina transformação econômica e política, ao mesmo tempo que exerceu papel de trampolim para a afetiva conquista do oeste do território sulino.

Condicionados não só pela estrutura geo-econômica e política da Capitania, como também pela conjuntura brasileira, alguns núcleos, identificados como áreas de produção ou postos militares, já delimitados como freguesias, 
sobrepuseram-se a outros. E a configuração deste quadro, já nos primórdios do século XIX, pode ser aferida pelo relato de Roscio:

As povoaçoens deste Governo se podem nomear pellas suas Paroquias, ou Freguezias, e são: A do Rio Grande de S. Pedro com duas Capellas Filiaes: hua no Povo Novo de Torotama: e outra no Canguçú: A Freguezia do Estreito com Capella na Povoação do Nórte do Rio Grande; A Freguezia de Mostardas; A de Viamão; A de Porto Alegre; a do Senhor Jesus do Triunfo; a do Taquary; A de Sto. Amaro; A do Rio Pardo com hua Capella Filial na Encruzilhada; A de Cachoeira, tăo bem tendo presentem te. Capella Filial em Caçapava; a de Sto. Antonio; a Freguezia de N.Senhora da Conceição do Arroio e ultimamente a dos Campos de Sima da Serra e Vaccaria: Sendo as mais concideráveis destas Povoaçoens a de Porto Alegre: a do Rio Grande, e a do Rio Pardo. Os demais estabelecimentos săo Fazendas de Gados, com poucos Povoadores, e alguns Escravos e Peaens. (28)

\section{E, nessa perspectiva de conjunto, no caso rio-grandense constata-se que}

(...) as principais atividades econômicas do fim do século XVIII e começo do XIX estavam polarizadas em torno de Rio Grande e de Porto Alegre, com significativas extensões em Rio Pardo que começava a polarizar, com as nucleaçoes vizinas, o». (29)

Salta aos olhos do pesquisador que examinar a documentação referente a essa fase a constância desse tratamento dado a três freguesias: Rio Grande, Porto Alegre e Rio Pardo. Nelas concentravam-se atenções governamentais, traduzidas na determinação de obras, de melhorias a serem feitas, criadas e atendidas.

As primeiras reclamações em favor da instrução do povo, feitas por Paulo da Gama, dirigiam-se para Porto Alegre, Rio Pardo e Rio Grande. Marques Fernandes, como Sargento-mor de Ordenanças, atendia a três povoações principais,

(...) que vem a ser em Porto Alegre, aonde reside a Junta da Real Fazenda, Rio Grande e Rio Pardo, (...) (30)

existindo em cada uma delas tropa e armazém da Real Fazenda e almoxarifes.

Esta importância é revelada ainda pela Tabela dos Rendimentos $\mathrm{daCa}$ pitania dos anos de 1809 e 1810 . A entrada aos cofres era feita basicamente por estas três freguesias, seja do rendimento do correio, seja do papel selado e outros.

Nesse sentido, como sócio e também por estar ligado à administração dos contratos do quinto, dizimo e munício da tropa de toda a Capitania, Manoel Antônio de Magalhães enfatizava o destaque das freguesias pela arrecadação, referindo sua população:

As quatro principais freguezias d'esta capitania todos os seus vigarios são igualmente vigarios da vara, năo só das suas freguezias, mas igualmente das outras mais pequenas que ficam nos seus competentes districtos. A freguezia do Rio Grande de S. Pedro é a maior da capitania, hoje excede a dois mil fogos e nove mil almas; rende de dez para onze mil cruzados. Esta da villa de Porto Alegre sóbe de mil e duzentos fogos, e seis mil almas, e rende annualmente de seis a sete mil cruzados. A do povo do Rio Pardo não tenho a certeza dos povos, nem das almas que tem; e só que o seu rendimento anda de cinco a seis mil cruzados. A do Bom Jesus do Triumpho tam- 
bém ignoro os povos que tem, a sua renda annual anda de um conto, a tres mil cruzados.

(...) Todas as mais freguezias da capitania săo mesmo (sic) rendosos, não passando a maior de 500, a $6000 \$ 000$. (31)

E mais adiante, o mesmo Magalhães, quando refere a fatura das vilas, preocupava-se, sobretudo, com a distribuição da justiça na Capitania, aliás um dos fundamentos que o governador Paulo Gama referiu em 1803, na sua proposição de se criarem vilas no Rio Grande de S. Pedro:

(...) feitas ellas, pelo menos se devem nomear para esta capitania tres juizes de fóra, o primeiro para esta villa de Porto Alegre, visto năo ter vindo o que se acha nomeado há quatro annos; e é pouco ser juiz de fóra de perto de três mil fogos e quinze para dezoito mil almas?

(...) o segundo para a villa do Rio Grande de S. Pedro, e mais povos d'aquella comarca, que contém perto de vinte mil almas, e acima de sessenta leguas de extensão, contadas desde a freguezia de Mostardas até a fronteira do Jaguarāo. O terceiro deve ser da comarca do $\mathbb{R}$ Rio Pardo, tendo de extensão mais de cem leguas com immensos povos debaixo da sua jurisdicção. (32)

Sem dúvida, os documentos confirmam a primazia, dentre as freguesias, existentes até a primeira década do século XIX, de especialmente três, a partir das quais as demais, pelas suas condições, eram polarizadas pelo triângulo: Rio Grande, Porto Alegre e Rio Pardo.

Essas condições inegavelmente lhes eram dadas de forma marcante pela rede de caminhos, principalmente por água: Rio Grande-Porto Alegre-Rio Pardo, caminho esse mais cômodo e econômico e, por isso, mais adequado, dadas as condições geográficas e econômicas da época, num território em que tudo estava por se fazer e promover.

Um exame a seguir, embora superficial, de cada uma destas três freguesias, complementará o todo numa visão de relações de conjunto.

RIO GRANDE, a fronteira do Rio Grande, fundada em 1737. com a instalação do Presídio Jesus Maria José, com a finalidade sobretudo de defesa contra seus insistentes vizinhos e assim também garantir e assegurar a Colônia do Sacramento, coube-lhe administrar o Continente de São Pedro, ganhando, dez anos depois, o título de vila.

Apesar da devassa sofrida em 1763 pela ação dos espanhóis, deslocando o centro governamental para a freguesia de Viamão, cresceu paulatimente sua importância comercial como porto, sobretudo motivado pela indústria saladeiril. Estabelecida em 1780, à margem direita do Rio Pelotas, tributário do São Gonçalo, ao sul da lagoa dos Patos, a mesma condicionaria a diretiva econômica do sudeste rio-grandense pelo século XIX.

Nesse sentido, o porto gaúcho, centro de exportação para outras Capitanias e para o exterior, ganhou dimensảo com a crise da carne seca do nordeste, que estimulou e valorizou a indústria saladeiril no sul. $\mathbf{E}$ as cifras de alguns produtos, nos anos de 1806 e 1807, confirmaram a importância comercial de Rio Grande (Tabela 1): 
TABELA 1

EXPORTAÇĀO DA PRAÇA DE RIO GRANDE NOS ANOS DE 1806 E 1807

\begin{tabular}{|c|c|c|c|c|c|}
\hline ANOS & COUROS DE BOI & CHARQUE & SEBO & TRIGO & CHIFRES \\
\hline $1806 \ldots$ & 185405 & 475258 & 36832 & 62863 & 232004 \\
1807. & 231784 & 600135 & 44712 & 93298 & 279620 \\
\hline
\end{tabular}

FONTE:

CHAVES, Antonio José Gonçalves. Memórias econômo-politicas. Reeditadas por J. B.

Hafkemeyer S.J. Revista do IHGRS. Porto Alegre, 6-7: 92, II e III trimestres, ano II, 1922.

Igualmente, era pelo porto de Rio Grande que entrava grande parte dos produtos importados:

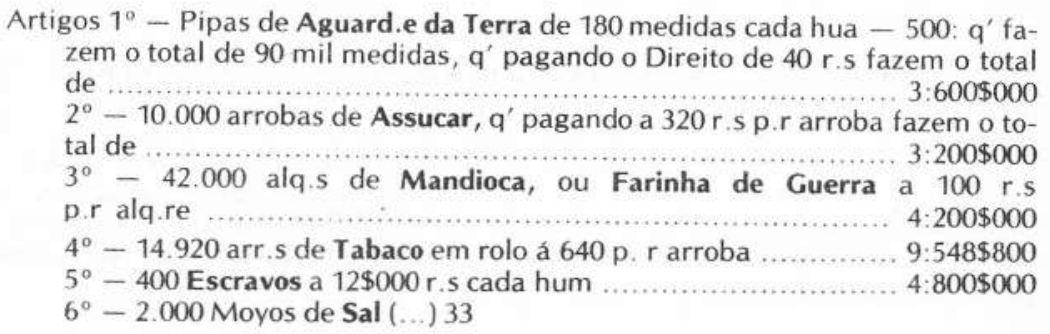

A partir destes e de outros dados, na perspectiva do crescimento visualizado pelo então governador, justificou novamente sua grande preocupação pela execução da justiça pelo ofício de 25 de agosto de 1804 ao Ministério dos $\mathrm{Ne}$ gócios Ultramarinos, no qual pediu a nomeação de um juiz letrado para a vila de Rio Grande.

Sem dúvida, a primeira vila do Continente fazia jus ao tratamento destacado que lhe era dado, não só pelo papel de defesa militar que exerceu no século XVIII, mas, também e principalmente, como entreposto comercial, cujos dados espelhavam os rumos da economia rio-grandense durante o século XIX.

Mas, seria PORTO ALEGRE, pela sua situação geográfica peculiar, que exerceria um papel singular na História rio-grandense, como vértice do ângulo que abraçava as duas fronteiras, Rio Grande e Rio Pardo, pois:

(...) quem examina uma planta de Porto Alegre da primeira metade do século passado e vê uma fortificaçāo fechando a ponta da peninsula pode atribuir o surgimento da povoação ali, às mesmas razões que fizeram surgir Montevidéu, Maldonado e Colónia do Sacramento no mesmo tipo de acidente geográfico: economia e rapidez na construção da defesa. Mas quando se situam no tempo e nas ocorrências de ordem politica, se convencerão que a razão foi bem diferente: imposiçōes de ordem geográfica determinaram naquele ponto a localização da capital para melhor atender as duas fronteiras em luta: Rio Grande e Rio Pardo. (34) 
Motivado nesse posicionamento, que as comunicações por água favoreciam, Porto Alegre logo adquiriu importância comercial considerável como Porto de escoamento da produção das povoações litorâneas e das imediações do Jacuí: Santo Antônio da Patrulha, Conceição do Arroio, Aldeia dos Anjos, Viamão, Rio Pardo, Santo Amaro, Taquari, Triunfo e Cachoeira.

Nestas circunstãncias, e como centro administrativo da Capitania, nela se instalou a primeira Alfândega rio-grandense, como também foi sede da Junta da Real Fazenda, que centralizava o controle da vida econômica rio-grandense, por ser a intermediária das determinações reais no setor.

Foi José Marcelino de Figueiredo que tratou de transferir de Viamão para Porto Alegre, em 1773, a sede do Continente, donde se passou a expedir ordens para as povoações.

A residência do governador é ordinàriamente em Pêrto Alegre, dali dá ordens a vários delegados, dos quais são principais dois, que residem, um na Vila de S. Pedro, outro em Rio Pardo. Também ali se acha estabelecido o senado da Câmara, e não há outro em toda a Capitania, com gravissimo prejuizo dos povos distantes daquela Vila. (35)

Igualmente nela se concentrava o reduzido atendimento judiciário:

(...) a mesma Vila é a maior povoação da Capitania, é tambám a que tem maiores edificios; e a única em que há justiças ordinárias de jurisdição real, com gravíssimo incômodo e prejuizo dos moradores na distância de setenta, oitenta e noventa léguas; e até do mesmo Estado, que perde muitos vassalos por falta de ministros de justiça, (...) (36)

Nesse sentido, os apelos, aos poucos, foram ressoando e a vara de Juiz de Fora em Porto Alegre foi criada em 26 de janeiro de 1803 e, posteriormente, a de Juiz de Fora do Civil, Crime e Orfãos, em 23 de agosto de 1808.

Empenhou-se Paulo da Gama em prover a capital de condições para seu funcionamento, inclusive no campo cultural. Com este intuito, reuniu no Palácio do Governo, em 21 de janeiro de 1804 , as principais personalidades de Porto Alegre para resolverem sobre a construção de um teatro, a criação de uma casa de baile e de um clube de letras. Já em 1800 existia uma aula prática de latim, do Pe. Tomé Luiz de Souza, que, conforme Provisão de 15 de outubro de 1803 , foi transformada em aula régia pública. Em 1807, o Almanaque de Porto Alegre refere a existência de uma aula pública de gramática e de duas escolas de ler e escrever na capital (37).

$\mathrm{E}$, assim, outras iniciativas e/ou órgãos administrativos iam sendo implantados: Intendência da Marinha, Ouvidoria da Comarca, além da criação do Hospital da Santa Casa de Misericórdia de Porto Alegre, conforme aviso de Lisboa de 14 de maio de 1803.

Dadas estas circunstâncias de crescimento e importância econômica e política que vinha tendo a sede do governo gaúcho, foi expedido, em 23 de agosto de 1808 , um alvará real, mandando elevar à vila a povoação de Porto Alegre, uma vez que o de semelhante tẹor, de 23 de janeiro de 1803, não tinha sido cumprido. Mas, ver-se-à que a palavra final seria dada com a Provisão de 7 de outubro de 1809 .

Finalmente, RIO PARDO, centro militar de resistência, pelo papel que 
exerceu de tranqueira do Rio Grande, apesar da paz de 1801, estava ainda, nesta primeira década do século XIX, meio indefinida, pois a integração definitiva de Missões não era obra de um ano e, sim de um processo que duraria mais de um século.

Após a conquista do território das Missões (1891), Rio Pardo se impôs como nucleação intermediária, pois recebia pelo rio os produtos dos centros agrícolas do corredor do Jacui e transportava-os aos núcleos da região missioneira, vezes outras interrompido por ameaças de disputa fronteiriça.

Apesar destes entraves militares, um observador da época, além de enaltecer alguns aspectos religiosos e situar sua jurisdição eclesiástica, previu prosperidade para aquela região, como disse:

A povoação de Rio Pardo é cabeça de comarca eclesiástica, ali reside o vigário da vara: a sua jurisdição se estende além das ditas freguesias de Rio Pardo e $\mathrm{S}$. Bárbara, à de N. Sra da Conceição da Cachoeira, (...) a sua igreja é a mais bem construida de tôda a Capitania, muito grande, segura e bem ornada: esta povoação dá esperanças de muito aumento pela grande aplicação que ali se observa dos seus habitantes à agricultura e capacidade do território para a produção; (...) (38)

Então, Rio Pardo, Posto do Jacuí, desempenhava o papel de núcleo intermediário por água, parł atender à grande região missioneira ou escoar seus produtos para Rio Grande e, por terra, de ponto de passagem de grande número de cabeças de mulas para São Paulo e outros pontos.

Assim, não são sem fundamento as afirmações de que Rio Pardo, Rio Grande e Porto Alegre foram, na primeira década do século XIX, os núcleos mais apreciáveis da Capitania, justificando sua escolha para a primeira rede de vilas.

Entretanto, como foi visto, não só pela proposição de Domingos José Marques Fernandes, mas sobretudo pela de Paulo da Gama, era proposta a criação de quatro vilas: Rio Grande, Porto Alegre, Rio Pardo e Santo Antônio da Patrulha, o que foi confirmado pela Provisão de 7 de outubro de 1809 (39).

Eis que surge uma indagação: a que se deve, dentro deste contexto, as poucas referências à freguesia de Santo Antônio da Patrulha? Qual a sua atuação econômica, politica ou militar para merecer sua elevação à vila? E, por conseguinte, que papel lhe reservava a preposição de Paulo da Gama, posteriormente confirmada em 1809 ? fora

E comprovado que, durante o século XVIII, Santo Antônio da Patrulha

(...) «porteira» de entrada e saida, posto fiscal de importância para a economia do vice-reinado (quintos da coroa) desde muito se tornara povoado singular no conjunto de nucleaçóes do Continente de São Pedro do Rio Grande. (40)

Era a freguesia de Santo Antonio da Guarda Velha a que polarizava os interesses da região nordeste. Mas é interessante observar que a Carta Geográfica de 1780, de Antônio Ignácio Rodrigues de Córdova, do Continente de São Pedro salientava, como povoaçôes principais, Rio Grande, Viamão, Rio Pardo e Vacaria.

Vê-se ai que maior importância era dada à zona de Cima da Serra do que, propriamente, à de Santo Antônio, pois 
(...) enquanto esta nucleação tinha importância para a Coroa como centro fiscal de pagamento dos Quintos, aquela reunia maior riqueza em gado. (41)

Entretanto, com o esvaziamento pecuário dos campos de Viamão, a agricultura firmou-se em SAP*, com o plantio da cana-de-açúcar.

Infelizmente, a escassez de dados de produção da Capitania, neste periodo, não permite um exame mais acurrado das diretrizes que nortearam a propagação da cultura da cana-de-açúcar nesta região. Além das revelações de Marques Fernandes, por um relato das Tabernas da Freguesia, expedido em 1806, é dada uma idéia, pelo seu número, do crescente interesse na região pelo fabrico da aguardente.

Eis o quadro:

Relação das Tavernas que exzistem no Destricto do meu Comando Freg ${ }^{\mathrm{a}}$. de $\mathrm{St}^{\circ}$. Anio. 30 de 7 tbro. 1806.

\begin{tabular}{|l|l|}
\hline \multicolumn{2}{|c|}{30 de 7tbro. 1806.} \\
\hline Nomes dos sugeitos aqm. pertencem & Lugar aonde exzistem \\
\hline Joze Bernardes Sanhudo & Ao pé do Passo da Miraguaya \\
Thomas Antonio & No Passo de Joze Pereira \\
Aviuva Anna Joaqna. de Azevedo & Em $/$ Roza Jeronima \\
Joaqum. Anio. de Figueiro & Dentro da Freg. ${ }^{{ }^{*}}$ \\
João da Roza da Silva & Dto. \\
Agostinho Ribro. & Dto. \\
O Preto forro Pedro & Dto. \\
Manoel de Castro Lima & Dto. \\
Maria Ignacia & Dto. \\
Antonio Ribro. Denis & Dto. \\
O Alfes. João Pinto da S & No Passo do R $^{\circ}$. do Sino \\
Franco. Xavier da Lús & Dto. \\
\hline
\end{tabular}

Observação

Além das q'asima vão nomiadas qdo. cheiga o Verão há mayor $n^{\circ}, \mathrm{E}$ na mayor parte $\cdot$ dos Injanhos se vende ag. de em medidas piquenas de meio quartilho $\mathbf{p}^{\mathrm{a}}$. sima, não vão nomiados os dtos. Injanhos por não saber se emtrão neste $n^{\circ}$.

Fonte: J unta da Real Fazenda, Representaçőes à Junta, 1806. Documento n. 156. AHRS.

A dita relação foi feita, a pedido da Junta, pelo encarregado da cobrança dos rendimentos do novo imposto de $16 \$ 000$ rs. de cada taberna ou loja de bebidas, relativo à freguesia de Santo Antônio, uma vez que os taberneiros se furtavam a pagar o dito, alegando

(...) de que não tinhăo nem vendiăo Agoardente, porque os donos dos Emgenhos a dispunhăo por meudo. (42)

E, em seu Retrospecto Econômico e Financeiro, Florêncio de Abreu confirma que, em principios do século XIX, em SAP, fabricava-se aguardente, rapaduras e açúcar em grande escala (43).

Mas é interessante observar que, na contribuição da Freguesia de SAP na forma de Dons Gratuitos, pedida pela Carta Régia de 6 de abril de 1804, para as urgentes precisões do Estado, não aparece a oferta de nenhum produto canavieiro, dentre as 153 contribuições, quais foram (Tabela 2): 


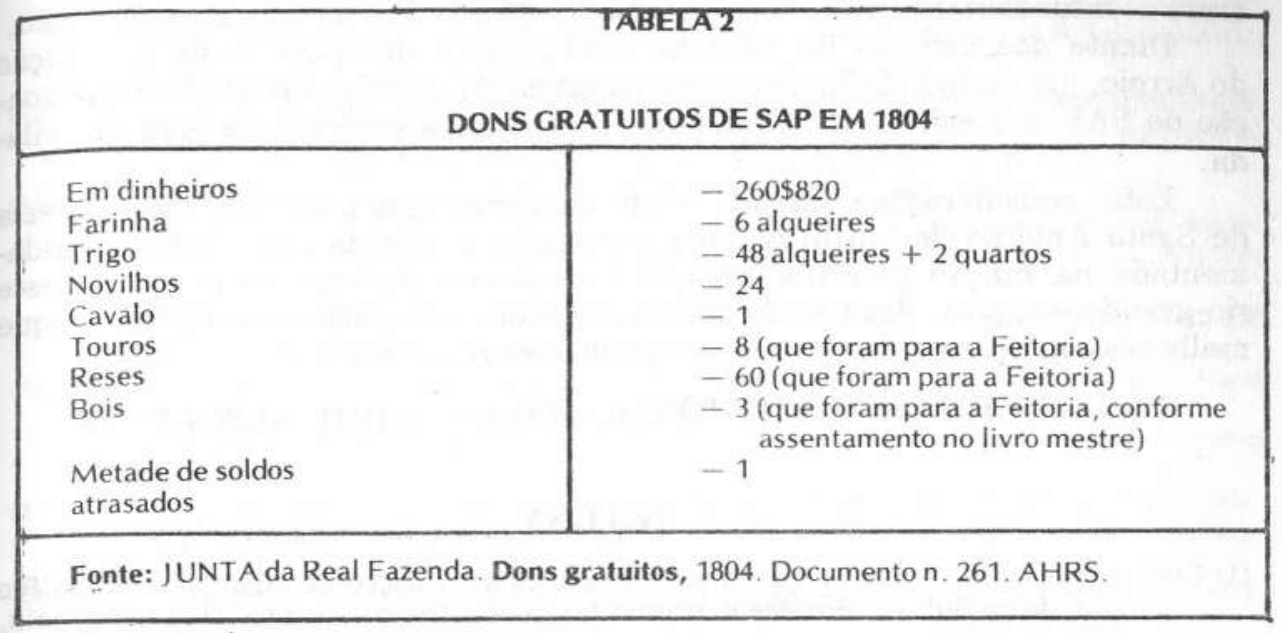

Outro aspecto das relações econômicas de SAP é o abastecimento da feitoria do Linho Cânhamo pela freguesia, conforme já denuciara a contribuição de 1804, e confirmado por outros documentos, como esta cópia de recibo:

Rce do Snr 'Manoel Nunes Bemfica m.or na Freguezia de Sto. Ant.o na sua Estancia Oitenta Rezez, de Corte, que conduzi $p^{a}$. a Real Feitoria do Linho Canhamo, para o sustento dos Individuos q'nella servem, as quais the tirei como Capataz da Estancia da $d^{a}$. Feitor ${ }^{2}$. em Vertude de hua Portaria, qe, $p^{a}$. o referido fim foi servido passar o llmo e Exmo. Snr. Ten.eGen.al G.or do Continente, e para qe. possa haver o pagamto. das $\mathrm{d}^{\mathrm{a}}{ }^{\mathrm{s}} \mathrm{s}$ Rezes aonde pertencer the passo o preze. q. só mente asigais 22 de Outubro 1799.

Franco. Lopes de Souza. (44)

Apesar destas considerações, no periodo de 1803-1809, o papel de SAP na Capitania era de uma povoação secundária, isto é, não estava listada dentre os núcleos de atendimento prioritário como Rio Grande, Porto Alegre e Rio Pardo.

Porém, a imensa área rio-grandense repartida em vilas exigia, para as povoações do nordeste, a polarização exercida por outra que não Porto Alegre, A esta estava reservada outra parcela territorial.

E, dentre as três freguesias da região nordeste: Conceição do Arroio, N. Sra. da Oliveira de Vacaria, era SAP a de mais prontas condições. Primeiro, era a mais populosa e, por isso, com melhores condições de formar Câmara. Em 1803, reunia 2.199 habitantes, enquanto Conceição do Arroio reunia 1.041 e Vacaria apenas 845 (45). Outros dados denunciavam esta primazia, principalmente nos quadros da arrecadação. Por exemplo: na contribuição de 1804, Conceição do Arroio se manifestou com 87 doações, referentes a 10 novilhos, 16 reses, 1 besta e 27 alqueires de farinha, além da soma de $519 \$ 940$ (46). Menores foram os números de Cima da Serra. Apenas 53 contribuintes se manifestaram, doando 27 reses, 8 potros e ..............314\$620rs (47).

Além disso, ligada a Vacaria e Conceição do Arroio, SAP estava na bifurcação dos caminhos, pois, de Conceição do Arroio a Vacaria, as comunicações 
eram acentuadamente dificeis, pela falta de estrada direta entre elas até então.

Diante dos campos de Vacaria, ainda muito desertos, e de Conceição do Arroio, um tanto indefinida entre o caminho do litoral desprezado e a povoação de SAP, era sobre esta última que iria recair a preferência para ser vilada.

Estas considerações parciais levam a concluir que a escolha da freguesia de Santo Antônio da Patrulha, para ser a quarta vila da rede, estava fundamentada na função polarizadora que lhe caberia exercer sobre o nordeste rio-grandense, pois, das três freguesias ali existentes, era, sem dúvida, a que melhores condições tinha para desempenhar-se como vila.

\section{PŌS-GRADUAÇĀO DE HISTÓRIA, PUC-RS - PORTO ALEGRE - RS}

\section{NOTAS}

(1) Com propriedade, Florêncio de Abreu exemplifica a formaçăo de algumas vilas do Rio Grande do Sul. In: Ensalos e estudos históricos. Rlo de Janeiro, Irmãos Pongetti, 1964. p. 143-4.

(2) No periodo colonial, geralmente se mandava fundar cidades (...) para atender a um plano consciente de estratégla ou da politica económica ou ecleslástica dos senhores da metrópole. OMEGNA, Nelson. A cidade colonial. $2^{2}$. ed. Brasilia, EBRASA/INLI MEC, 1971. p. 7.

(3) As sesmarias caracterizadas em estâncias de cunho latifundiário pelo estabelecimento da pecuária dificultava a proliferaçăo de núcleos populacionais. Já as datas de terras doadas aos açorianos no caso rio-grandense, pela sua característica minifundiária

e agrícola, facilitavam, pelas trocas comerciais, a formação mais rápida extensiva de agrupamentos urbanos.

(4) OMEGNA, op. cit. nota 2, p. 78.

(5) AZEVEDO, Fernando de. A cultura brasileira. 5 ed. rev. aum. São Paulo, Melhoramentos/USP, 1971. p. 149 (Col. Obras Completas, 13).

(6) No período colonial, a distinção entre vida e cidade não era de ordem administrativa e sim de dignidade. BANDECCHI, Brasil. O municipio no Brasil e sua função política. Revista de Histórla. São Paulo, XI, 1974 (nota 118).

(7) Sobre este assunto existe o interessante trabalho publicado pelo IGRA, com a colaboraçāo da Ação Moageira de Fomento do Trigo Nacional, intitulado Regióes polarizadas e homogêneas, existente na Biblioteca do IEPE-UFRGS.

(8) No periodo colonial, a criação de uma vila resultava de um ato régio. Durante o Império, houve variaçőes. No Rio Grande, após a Revolução Farroupilha e até a proclamação da República, há certa estabilidade, pois todos os municiplos foram criados através de leis da Assembléia Legislativa. BORGES FORTES, Amyr \& WAGNER, J.B.S. História administrativa, Judiclárla e ecleslástica do Alo Grando do Sul. Porto Alegre, Globo, 1963. p. 12-3.

(9) O primeiro vilamento de Vacaria al se posiciona.

(10) Por exemplo, a instalação da primeira rede de vilas criadas em 1809 arrastou-se até 1811.

(11) Sobre o assunto existe a importante obra de Brasil Bandecchi, citada no nota 6.

(12) Reformulada em parte pelo Ato Adicional de 1834, Lel Regencial $n^{\circ} 16$, de 12 de agosto.

(13) Para a explicitação das funçర̄es dos auxiliares da administraçăo municipal, podem ser examinados os trabalhos de:

Zenha, Edmundo. O municiplo no Brasll, 1532-1700. Săo Paulo, Instituto Progresso, 1948;

MONTEIRO, Antenor de O. Os homens do segundo vilamento do Rio Grande. RIHGRS. Porto Alegre, 105-108: 123-32, 1947.

(14) FALLA dirigida à Assembléla Legislativa da Provincia de S. Pedro do Río Grande do 
Sul pelo Presidente Conselheiro Jerônimo Martiniano Figueira de Mello em a segunda sessão da $14^{\circ}$. legislatura. Porto Alegre, Typographya do Rio-grandense, 1872. p. 51-2. (o grifo é nosso).

(15) ATA da sessão da Assembléla em 10 de dezembro de 1888. Annaes da Assembléa Legislativa Provinclal da Provincia de S. Pedro do Rlo Grande do Sul, 24* legislatura, $2^{\mathrm{a}}$. sessão de 1888. Porto Alegre, Typographya da Reforma, s.d. p. 76.

(16) Temática desenvolvida na dissertação de mestrado da autora. Examinar:

BARROSO, Véra llúcia Maciel. Santo Antónlo da Patrulha - vinculo, expansăo isolamento: 1803-1889. Dissertação de mestrado em Cultura Brasileira. Porto Alegre, PUC-RS, 1979.

(17) Tomou posse como governador em Porto Alegre a 30 de janeiro de 1803, governando até 9 de outubro de 1809.

(18) Em Porto Alegre, produzia-se muito trigo e ensaiavam-se a cana e a vinha. A fruticultura era variada, e as hortas abundantes. A respeito, examinar:

SANMARTIN, Olyntho. Aspectos econômicos da velha Porto Alegre. RIHRGS. Porto Alegre, 89:126, 1943.

(19) OFICIO do Governador da Capitania ao Visconde de Anádia em 25 de julho de 1803. Correspondência envlada às autoridades do Rlo de Janeiro. Autoridades diversas, 1802-1812. p. 12-3. v. 4. AHRS

(20) OFÍCIO do Governador da Capitania ao Visconde de Anádia em 25 de julho de 1803. Ibidem, p. 15.

(21) Composta de 36.721 almas, conforme o Mapa das Freguesias, com exceção dos nascidos em 1803 e tropa de linha.

OFICIO do Governador da Capitania ao Visconde de Anádia em 4 de dezembro de 1803. Ibidem, p. 25.

(22) Ibidem. (o grifo é nosso).

(23) Natural do Couto de Săo Salvador de Pedralva em Portugal, vindo para Porto alegre exerceu o ofício de escrivão de sesmarias em 1789.Fol em 1804 pleitear, junto ao soberano, a divisăo da Capitania rio-grandense em quatro municipios. Em 1808, com a vinda da familia real, retornou ao Brasil, quando foi provido na serventia do oficio de escrivão da Ouvidoria Geral do Crime e depois da Correição do Crime da Corte no Rio de Janeiro, deixando de exercê-lo em 1822. Em 1828, foi juiz de Paz da Câmara do Rlo. Presume-se tenha falecido depois de 1842.

Revista Pesquisas, História 15. Porto Alegre, Universidade do Rio Grande do Sul, Instituto Anchietano de Pesquisas: 6-7, 1961. Neste número, está publicada a descrição de Marques Fernandes.

(24) Ibidem, p. 82-3. (o grifo é nosso).

(25) MAGALHÃES, Manoel Antônio de. Almanaque da vila de Porto alegre, com reflexões sobre o estado da Capitania do Rio Grande do Sul, Porto alegre, 1808. Boletim Municipal. Porto alegre, 5:264, maio/ago, 1940.

(26) COIMBRA. Créso. Fenomenologia da cultura brasileira. São Paulo, Lisa Livros Irradiantes, 1972 p. 331.

(27) Sobretudo pelo comércio do gado e seus derivados.

(28) ROSClO, Francisco João. "O compêndio noticloso do Continente do Rio Grande de S. Pedron e outros documentos de Francisco João Roscio. RIHGRS, cit., nota 13. p. 83. (o grifo é nosso).

Complementa os dados de Roscio a descrição de Marques Fernandes: Haverá nesta Capitania cinqüenta mil almas, dlstribuidas em vinte $\theta$ uma freguesias, cujas igrejas paroquiais săo quatorze matrizes e sete fllials; (...)

Rev. cit., nota 22, p. 33.

(29) MACEDO, F. Riopardense. Primeiras atividades econômicas. Correio do Povo. Porto Alegre, 28 jul. 1973, Caderno de Sábado. p. 16. Parecer confirmado por Fernandes: A malor parte desta gesta está reduzida a povoaçōes; destas săo três as principais, a saber: S. Pedro do Sul, Rlo Pardo e Porto Alegre.

Rev. cit., nota 22, p. 33.

(30) REPRESENTAÇĀO de Domingos José Marques Fernandes, anexa ao Aviso de 6 de março de 1805. Avisos do Governo, 1804-1807. Documento n. 21. AHRS.

(31) MAGALHÃES, op. cit., nota 24, p. 256-7.

(32) Ibidem, p. 264-5.

Quanto à jurisdiçăo de Rio Pardo, com a conquista das Missōes (1801), sua área já 
correspondia ao território inteiro a oeste, desde o braço do Jacul, nas direçס̋es norte e sul.

(33) IMPORTAÇĀO do Río Grande no ano de 1800. Avisos do Governo, 1800-1803. Documento n. 60 (anexo 2). AHRS. (o grifo é nosso).

(34) MACEDO, F. Riopardense de. Urbanização, história e revoluçăo urbana. Correlo do Povo. Porto alegre, 7 abr. 1973. Caderno de Sábado, p. 16.

(35) FERNANDES, Domingos José Marques. Descriçåo corográfica, politica, civil e militar da Capitania do Rio Grande de S. Pedro do Sul. Rev. cit., nota 22, p. 38 . (o grifo é nosso).

(36) Ibidem, p. 37.

Observa-se que o parecer de D.J.M. Fernandes não é o mesmo que o de Manuel Antônio de Magalhães quanto à maior povoação da Capitania. Este último aflrma ser Rio Grande maior que Porto Alegre.

(37) MAGALHĀES, op. cit., nota 24, p. 273.

(38) FERNANDES, rev. cit., nota 22 , p. 40-1.

(39) $\mathrm{Na}$ integra, acha-se transcrita na obra de Amyr Borges Fortes e João B.S. Wagner, História administrativa, Judiclárla e eclesiástica do Rlo Grande do Sul, citada no nota 8, p. 36-8.

(40) MACEDO, jor. cit., nota 33, p. 16.

(41) MACEDO, F. Riopardense de. Os caminhos da conquista. Correlo do Povo. Porto Alegre, 21 jul. 1973. Caderno de Sábado, p. 16.

"Santo Antônio da Patrulha.

(42) JUNTA da real Fazenda. Representaçбes à Junta, 1806. Documento/n. 156. AHRS.

(43) ABREU E SILVA, Florencio C. Retrospecto econômico e financeiro do Rio Grande do Sul 1822-1922. Revista do Arquivo Público do Rlo Grande do Sul. Porto Alegre, Globo, 8:284, dez. 1922.

(44) JUNTA da Real Fazenda. Dons gratultos, 1803. Documento n. 406 (anexo). AHRS.

(45) MELLO, Homem de. Índice chronológico dos fatos mais notáveis da história da Capitanla depois Provincla de S. Pedro do Rio Grande do Sul Revista trimestral do

IHGEB. Rio de Janeiro, Typ. de Pinheiro \& C., tomo/XLII,parte II: 126, 1879.

(46) JUNTA da Real Fazenda. Dons gratuitos, 1804. Documento n. 294. AHRS.

(47) Ibidem. Documento n. 300. AHRS.

\section{BIBLIOGRAFIA}

\section{Obras}

1. ABREU, Florêncio de. Ensaios e estudos históricos. Río de Janeiro, Pongetti, 1964.

2. AZEVEDO, Fernando de. A cultura braslleira. 5 ed. rev. aum. São Paulo, Melhoramentos/USP, 1971. (Col Obras Completas, 13).

3. BORGES FORTES, Amyr \& WAGNER, J.B.S. História administrativa, judiciária e eclesiástica do Rlo Grande do Sul. Porto Alegre, Globo, 1963.

4. COIMBRA, Créso. Fenomenologla da cultura brasileira. São Paulo, Lisa Livros Irradiantes, 1972.

5. IGRA. Divisăo de Geografia e Cartografia. Evoluçăo administrativa do Rlo Grande do Sul; criação dos municipios. Porto Alegre, Secretaria da Agricultura, s.d.

6. OMEGNA, Nelson. A cidade colonial. 2. ed. Brasilia, EBRASA/IEL/MEC, 1971.

7. ZENHA, Edmundo. O municiplo no Brasli; 1532-1700. Sảo Paulo, Instituto Progresso, 1948.

Anais - Falas

1. ANAIS da Assembléia Legislativa Provincial da Provincia de S. Pedro do Río Grande do Sul, $24^{2}$. legislatura, $2^{a}$. sessão de 1888. Porto Alegre, Tipografia da Reforma, s.d. 
A formação da primeira rede...

2. FALA dirigida à Assembléia Legislativa da Provincia de S. Pedro do Rio Grande do Sul pelo Presidente Conselheiro Jerônimo Martiniano Figueira de Mello na $2^{\mathrm{a}}$ sessão da $14^{2}$. legislatura. Porto Alegre, Tipografia do Rio-grandense, 1872.

Jornais

1. CORREIO DO POVO. Porto Alegre, Caderno de Sábado, 7 abr. 1973; 21 jul. 1973.

\section{Boletins - Revistas}

1. BOLETIM MUNICIPAL. Porto Alegre, 5, maio/ago. 1940.

2. REVISTA DE HISTÓRIA. São Paulo, USP, XL, 1974.

3. REVISTA DO ARQUIVO PÚBLICO DO RIO GRANDE DO SUL. Porto Alegre, 8, 1922.

4. REVISTA DO INSTITUTO HISTÓRICO E GEOGRÁFICO DO RIO GRANDE DO SUL. Porto Alegre, 6-7, 1902; 89, 1943; 105-108, 1947.

5. REVISTA PESQUISAS. História 15. Porto Alegre, Universidade do Rio Grande do Sul, Instituto Anchietano de Pesquisas, 1961.

6. REVISTA TRIMESTRAL DO INSTITUTO HISTÓRICO, GEOGRÁFICO E ETNOGRÁFICO BRASILEIRO. Rio de Janeiro, Tipografia de Pinheiro \& C., tomo XLII, parte II, 1879.

\section{Arquivo Histórico do Rio Grande do Sul - documentos}

1. AVISOS DO GOVERNO, 1800-1803; 1804-1807.

2. CORRESPONDÊNCIA ENVIADA ȦS AUTORIDADES DO RIO DE JANEIRO. Autoridades Diversas, 1802-1812. v. 4.

3. JUNTA DA REAL FAZENDA. Representaçס̄es à Junta, 1804, 1806; Dons Gratuitos, $1803,1804$. 